\title{
Comparative study of Mirs'(Mushtaq and Shabir) technique of prepuce preserving minimally invasive urethroplasty with Snodgrass urethroplasty for repair of distal hypospadias without chordee...A prospective study
}

\author{
Mushtaq Mir, Shabir Ahmad Mir, Muddassir Shahdhar, Mumtazdin Wani, Hakim Adil Moheen ${ }^{1}$, \\ Jahangeer Ahmad Bhat ${ }^{2}$ \\ Departments of Surgery and ${ }^{2}$ Radiodiagonosis, Government Medical College, ${ }^{1}$ University of Kashmir, Srinagar, Jammu and \\ Kashmir, India
}

Address for correspondence: Dr. Shabir Ahmad Mir, Department of Surgery, Government Medical College, Srinagar, Jammu and Kashmir, India. E-mail: drshabirmir@gmail.com

\section{ABSTRACT}

Background: There is no single, universally applicable technique for hypospadias repair and numerous techniques have been practised from time to time. We compare the results of our new technique (Mirs' technique also called Mush \& Shab's technique) to Snodgross urethroplasty. Mirs' technique is a modified version of Thiersch-Duplay urethroplasty. Material and Methods: This prospective comparative study was carried out in a tertiary care hospital of Northern India over a period of 3 years from March 2010 to March 2013 and included 120 patients of anterior (distal penile, subcoronal, coronal and glanular) hypospadias without chordee. They underwent either Mirs' technique (group $1 n=60$ ) or Snodgrass technique (group $2 n=60$ ). Follow-up was at 1-week, 1-month, 3 months and 6 months. Results: The mean operative time was $55 \mathrm{~min}$ (range: 43-70 $\mathrm{min}$ ) in group 1 and $71.9 \mathrm{~min}$ (range: 60-81 min) in group $2(P<0.001)$. Urethrocutaneous fistula developed in two and four patients in group 1 and 2 , respectively. Fistula closure was done at least 3 months postoperatively, and there was no significant difference in success rate between the two groups. Three cases of glanular dehiscence were detected (one in group 1 and two in group 2); the patient from group 1 had a successful repair using the already preserved prepuce. Conclusion: Mirs' modification of Thiersch-Duplay technique for distal hypospadias is a time saving procedure with a lower overall complication rate. Valuable local tissue is preserved to deal with any complication that may occur. Analgesic requirement was significantly lower in this minimally traumatic technique. As it is less time consuming, simple and easy to learn with a short learning curve, this technique deserves application in cases of distal hypospadias.

\section{KEY WORDS}

Mirs' technique, prepuce preserving, Snodgrass technique

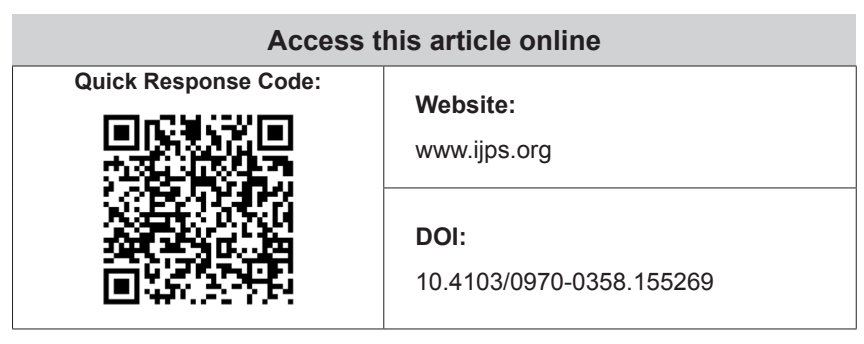

Indian Journal of Plastic Surgery January-April 2015 Vol 48 Issue 1

\section{INTRODUCTION}

The term hypospadias is derived from Greek and refers to a rent (spadon) on the ventrum of the penis. Hypospadias results when fusion of the urethal folds is incomplete. Hypospadias are relatively common congenital defect of male external genitalia. $80 \%$ of 
patients with hypospadias have a meatus in a coronal or subcoronal position. ${ }^{[1]}$ A number of surgical procedures and technical modifications for distal hypospadias has been developed and refined through the years to allow for a simple single stage repair that has lessened patients' discomfort and decreased complications and cost effectiveness without sacrificing functional and cosmetic results. ${ }^{[2]}$ Tubularised incised plate (TIP) repair described by Snodgrass in 1994 provides a technique with a possible low complication rate for correcting distal hypospadias, creating a neourethra of normal diameter irrespective to the plate, glans configuration and location of the meatus. ${ }^{[3]}$

The aim of the present study was to evaluate the results of a new technique (Mirs' Technique) which is a modified version of Thiersch-Duplay urethroplasty, in comparison to the Snodgross urethroplasty.

\section{MATERIALS AND METHODS}

This prospective comparative study was carried out in a tertiary care hospital of Northern India over a period of 3-year from March 2010 to March 2013, included 120 patients of anterior (distal penile, subcoronal, coronal and glanular) hypospadias without chordee. We assigned patients in two groups, group $=1$ and group $=2$, each group having 60 patients. They underwent either Mirs' technique (group $1 n=60$ ) or Snodgrass technique (group $2 n=60$ ). Follow-up was at 1-week, 1-month, 3 months and 6 months.

Mirs' technique (named after first and second author who gave this technique)
This technique also called Mush and Shab's technique is used for anterior (distal) types of hypospadias that is glanular, coronal and subcoronal. This technique is a prepuce preserving minimally invasive modification of ThierschDuplay technique. Proposed urethral plate is outlined at a width of 9-12 mm depending on the age of patient and size of the phallus, by two iongitudinal lines which are joined by a transverse line proximal to meatus. Stay suture is placed at the tip of glans. Cathterisation is done with a 6-8 $\mathrm{Fr}$ Silastic cathter (Haiyan Kangyuan Medical Instruments Co. Ltd, China). Incision is made along the proposed markings and the urethal plate is tubularised over the cathter by continuous through and through polyglactin inverting suture, with care not to close the distal extent (meatus) too tightly. Second layer coverage of neourthra is derived from adjacent facial tissues (Dartos + Bucks fascia) in the region of shaft, and deep glanular tissues in the glanular part, using interrupted $6 / 0$ polyglactin sutures. The third layer is derived from approximation of skin over the second layer [Figures 1-4].

Patients are discharged the next morning. Catheter is removed after 1-week on the first follow-up.

The advantages with this technique are minimal tissue trauma, no degloving of shaft skin, no undermining of the urethral plate or lateral skin flaps, no midline incision of the urethral plate, no sealing flap from prepuce and no disturbance of prepuce.

Minimal the tissue trauma, lesser the vascularity is compromised and better will be a healing process. This minimal disturbance of anatomy in the first instance does not hamper the results of further interventions if needed.
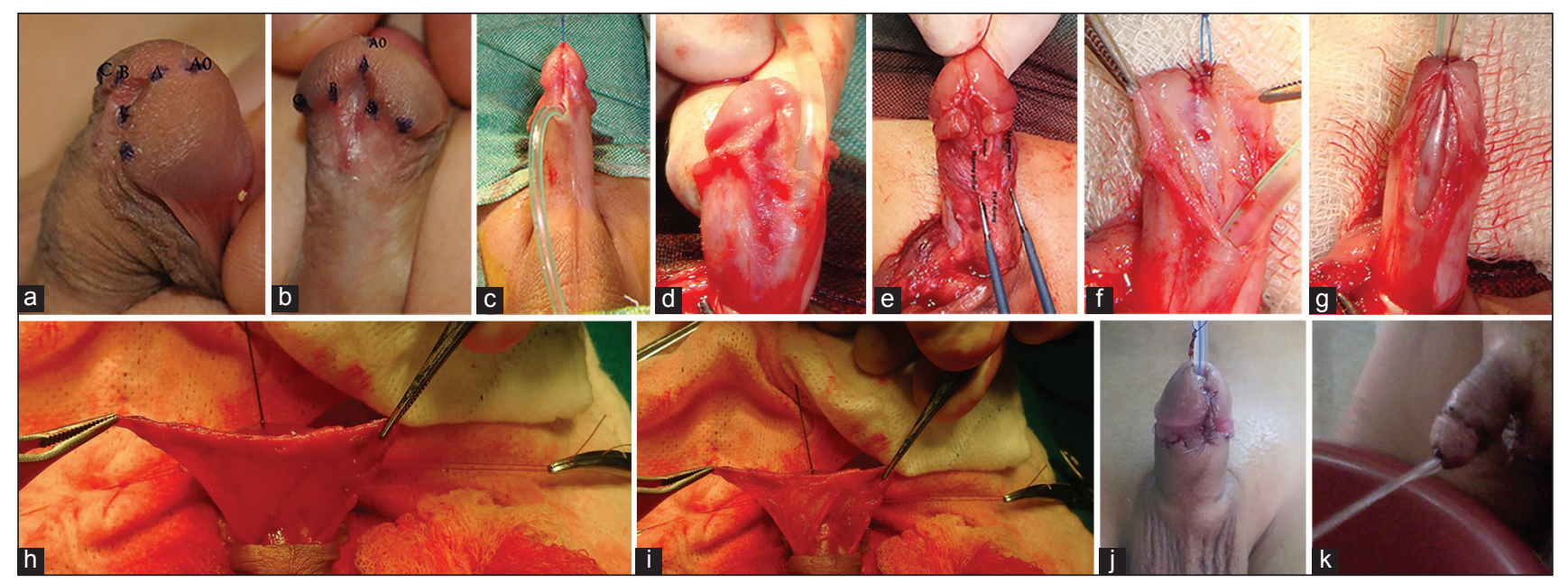

Figure 1: (a-k) Demonstrate the various steps of Snodgrass technique 


\section{RESULTS}

The mean age of the patients was 4 years (range: 2-6 years). The maximum number of cases were distal penile type ( $n=25$ in each group). The mean operative time was $55 \mathrm{~min}$ (range: $43-70 \mathrm{~min}$ ) in group 1 and $71.9 \mathrm{~min}$
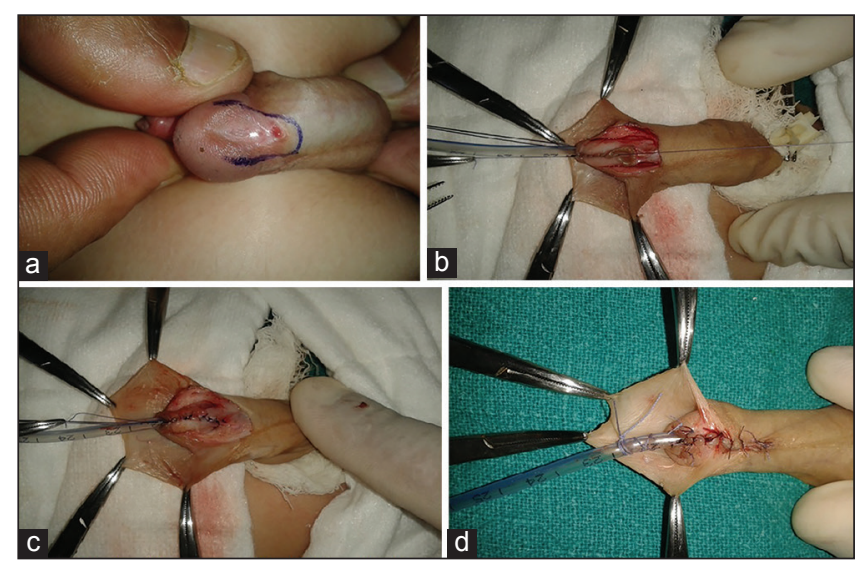

Figure 2: (a-d) Demonstrate the various steps of Mirs' technique

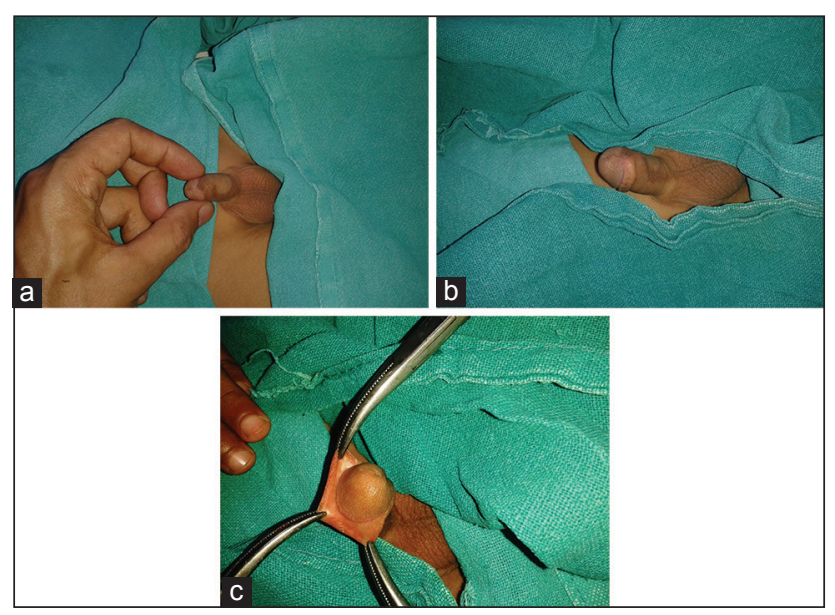

Figure 3: (a-c) Demonstrate the postoperative photographs of Mirs' technique

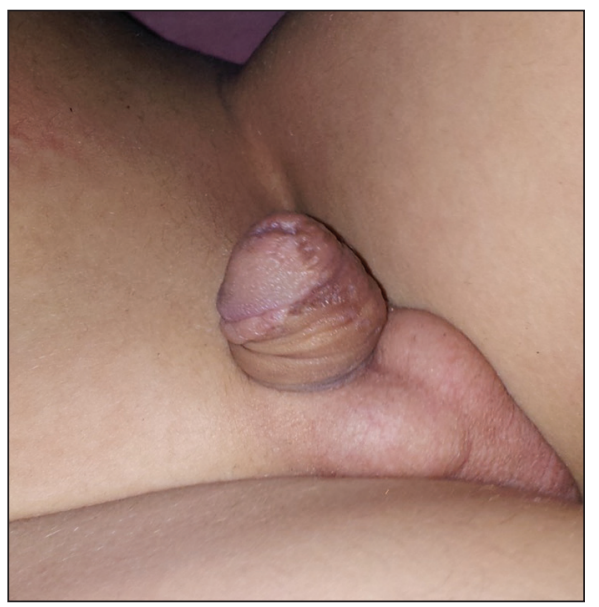

Figure 4: (a) Demonstrate the postoperative photograph of Snodgrass technique (range: 60-81 min) in group $2(P<0.001)$ [Tables $1-3$ ]. Urethrocutaneous fistula developed in 2 and 4 patients in group 1 and 2, respectively. Fistula closure was done at least 3 months postoperatively and there was no significant difference in success rate between the two groups. Three cases of glanular dehiscence were detected (one in group 1 and 2 in group 2); the patient in group 1 had a successful repair using the already preserved prepuce. Analgesic requirement was significantly lower in group 1 patients compared to group 2 patients. There was transit prepucial oedema in 13 patients in group 1 due to tight dressing, as compared to 4 patients in group 2 , the other complications like haematoma, infection, dehiscence and gangrene of skin flaps was less in our group compared to Snodgrass class but not reaching the statistical significance. Meatal stenosis occurred in 3 patients in group 1 as compared to only 1 patient in group 2 . These patients were managed by regular meatal dilatations with good results.

The patients from both the groups were mostly discharged in the next morning following the operative procedure, only few patients' from both groups required discharge with some delay.

One patient from group 1 and eight patients from group 2 had some analgesic requirement in the immediate postoperative period.

Data were analysed with help of means, standard deviations and percentage statistics. For parametric data, Student's $t$-test was applied for nonparametric data, Chisquare or Fischer exact test, whichever appropriate, was used. $P<0.5$ was considered statistically significant. Statistical software SPSS 16.0 was used to carry out the statistical analysis.

\section{DISCUSSION}

The majority of boys with hypospadias have a distal meatus with minimal chordee. ${ }^{[1]}$ There are various surgical procedures to correct such defects. The choice of operation for repair of distal hypospadias is determined

Table 1: Type of hypospadias and number of cases studied

\begin{tabular}{lcc}
\hline Type of hypospadias & Group 1 & Group 2 \\
\hline Distal penile & 25 & 25 \\
Subcoronol & 20 & 20 \\
Coronal & 12 & 12 \\
Glanular & 3 & 3 \\
\hline
\end{tabular}


Table 2: Complications

\begin{tabular}{|c|c|c|c|}
\hline Type of complication & $\begin{array}{c}\text { Group } 1 \text { (Mirs' technique) } \\
\text { number of patients }\end{array}$ & $\begin{array}{c}\text { Group } 2 \text { (Snodgrass } \\
\text { technique) number of patients }\end{array}$ & $P$ \\
\hline Prepucial edema & 13 & 4 & 0.036 (significant) \\
\hline Haematoma & 1 & 2 & 1.00 \\
\hline Infection & 1 & 2 & 1.00 \\
\hline \multicolumn{4}{|l|}{ Dehiscence } \\
\hline Partial & 1 & 2 & 1.00 \\
\hline complete & 0 & 0 & \\
\hline Gangrene of skin flaps & 0 & 2 & 0.496 \\
\hline Meatal stenosis & 3 & 1 & 0.619 \\
\hline Urethrocutaneous fistula & 2 & 4 & 0.679 \\
\hline Catheter blockage & 2 & 2 & 1.00 \\
\hline Postoperative penile rotation & 0 & 2 & 0.496 \\
\hline Analgesic requirements & 1 & 8 & 0.032(significant) \\
\hline Unsatisfactory cosmetic appearance & 2 & 2 & 1.00 \\
\hline
\end{tabular}

Table 3: Operative time

\begin{tabular}{lccccc}
\hline $\begin{array}{l}\text { Operative } \\
\text { time }\end{array}$ & $\begin{array}{c}\text { Number of } \\
\text { patients }\end{array}$ & $\begin{array}{c}\text { Mean } \\
\text { operative time }\end{array}$ & SD & Range & $\boldsymbol{P}$ \\
\hline $\begin{array}{l}\text { Mirs' technique } \\
\text { (Group 1) }\end{array}$ & 60 & 55.0 & 4.059 & $43-70$ & $<0.001^{*}$ \\
$\begin{array}{l}\text { Snodgrass } \\
\text { technique }\end{array}$ & 60 & 71.9 & 4.685 & $60-81$ & \\
(Group 2) & & & & & \\
\hline * & & & & & \\
\hline
\end{tabular}

*Statically significant difference. SD: Standard deviation

by a number of factors including the configuration of the glans and meatus and associated degree of penile curvature. Another important consideration in hypospadias surgery is the final cosmetic result. The ultimate goal is a penis that is not only functionally normal but cosmetically as well. Complications are common after hypospadias repair, ranging from fistula to complete loss of the neo-urethra requiring total reconstruction.

In 1994, Snotgrass described TIP urethroplasty for distal penile hypospadias repair. It was subsequently applied to proximal hypospadias with encouraging results. ${ }^{[3,4]}$ The technique is now widely accepted. ${ }^{[5]}$

An important step in the Snodgrass repair is the interposition of a barrierlayer(flap) between the neourethra and the overlying skin in order to decrease the rate of urethrocutaneous fistula formation. The most popular flap used is the preputial flap; however, mobilisation and ventral transposition of the flap around one side of the penile shaft may cause penile torsion, especially if the flap is of inadequate length and laid on with tension. Moreover, dissection of the flap may jeopardise the blood supply to the dorsal skin, which is often used for resurfacing closure, and may thus predispose to skin loss and failure of the repair. To avoid penile torsion, a modification of the way in which the preputial flap is immobilised has been described..$^{[6]} \mathrm{A}$ window is created in the flap at the midline, and the penile shaft is pulled through it in order to transfer the dartos flap ventrally over the neourethra. The size of the flap may, however, be inadequate to cover the repair when the ventral skin is deficient, and another modification in flap creation was described, which is to raise the ventral dartos flap to cover the neourethra. This technique was claimed to be associated with a low fistula rate and easier harvesting and mobilisation of the flap to cover the neourethra. ${ }^{[7,8]}$ Our technique preserves the prepuce. We achieved excellent results without using the preputial flaps.

Difference between Mirs' technique and Snodgrass technique:

- No midline incision is made in Mirs' technique as compared with Snodgrass technique.

- Prepuce is not disturbed at all in Mirs' technique whereas in Snodgrass technique sealing flap is dissected from the prepuce.

- No degloving of the penis and creation of Byars flap is done in Mirs' technique whereas in Snodgrass technique there is complete degloving of the penile shaft and creation of Byars flaps.

The central focus of our technique is to make a minimally invasive procedure which does not disturb the natural anatomical planes of the organ beyond what is required to correct the defect. The defect in the distal penile hypospadias without chordee for which we have recommended the procedure is failure of tublisation of the distal urethral plate, otherwise the tissues are adequate. Hence, we are assisting the nature in tubularsing the deficient portion of distal urethral plate without disturbing the rest of the organ.

Indian Journal of Plastic Surgery January-April 2015 Vol 48 Issue 1 
Another factor that may affect penile alignment is the degree of penile skin degloving during hypospadias repair: Complete degloving to the penoscrotal junction or limited to the area around the urethral meatus. Turial et al. ${ }^{[9]}$ recommended limited degloving of the penile skin in order to limit the need for a large covering layer of the neourethra, whereas Sozubir and Snodgrass ${ }^{[10]}$ performed complete degloving of the penile skin to provide full erection and prevent postoperative torsion or chordee. We achieved results comparable to Snodgrass technique without degloving the penile skin, thereby not only save the operative time but also give less trauma to phallus.

We stented all patients in both groups for about 1-week, which allowed drainage of the urinary bladder and prevented voiding due to the surgery. It also helps haemostasis, reduces postoperative bleeding and in the same time this short period, avoids the problem of catheter blockage and bladder irritation. Proponents of stenting argue that it keeps the dorsal midline incision stretched open and limits premature healing, which would obviate the benefit of the dorsal incision. ${ }^{[1]}$

We found that Mirs' technique has success rate similar to Snodgrass technique. Mirs' technique takes less time than Snodgrass technique $(P<0.001)$. Mean operative time in group 2 (Snodgrass group) in our study was $71.9 \mathrm{~min}$ which is comparable to mean operative time in another study. ${ }^{[12]}$ Complications like haemotoma, infection, dehiscence and gangrene of skin, urethrocutaneous fistula were less frequent in Mirs' technique compared to Snodgrass technique. Among these analgesic requirement $(P=0.32)$ reached the statistical significance. However meatal stenosis occurred in three patients in case of Mirs' technique, whereas only one patient developed meatal stenosis in Snodgrass technique. These cases of meatal stenosis were managed by regular meatal dilatations with good results. Meatal stenosis $(P=0.619)$ was not statically significant. Transient prepucal oedema was significantly $(P=0.036)$ more common in Mirs' technique (group 1) as compared to Snodgrass technique (group 2). This was less in group 2 because prepuce is not usually preserved in Snodgrass technique. Rate of fistula in group 2 in our study was $6.66 \%$.Similar results were present in other studies. ${ }^{[13-15]}$ Meatal stenosis was present in $1.6 \%$ of patients in group 2 in our study. Comparable results were shown by another study. ${ }^{[16]}$ Unsatisfactory cosmetic appearance was present in 3.33\% of patients in group 2 in our study which is comparable to another study by Roy and Saha. ${ }^{[13]}$ Glanular dehiscence occurred in 3.33\% patients in group 2 in our study which is also comparable to other studies. ${ }^{[12,13]}$ Postoperative Penile rotation and cathether blockage occurred in 3.33\% patients each in group 2 in our study which is comparable to the study by Alsharbaini and Almaramhy. ${ }^{[16]}$

\section{CONCLUSION}

Our technique (Mirs' technique also called Mush and Shab's technique) is providing results comparable to Snodgrass urethroplasty with few added advantages. One of the main advantages being that the technique is simple and easy to learn and thus short learning curve. It is time saving, requires less analgesic in the postoperative period and preserves the precious prepuce. The other advantages with Mirs' Technique are

- There is minimal tissue trauma

- No degloving of shaft skin,

- No undermining of urethal plate or lateral skin flaps,

- No midline incision of urethal plate,

- No sealing flap from prepuce,

- No disturbance with prepuce.

Hence, cases of distal hypospadias should also be corrected by our technique so that it will benefit the patients and reduce the operative time.

\section{REFERENCES}

1. Devine CJ Jr, Allen TD, Duckett JW, Horton CE. Hypospadias. Dial Ped Urol 1978;1:2-4.

2. Mitchell ME, Kulb TB. Hypospadias repair without a bladder drainage catheter. J Urol 1986;135:321-3.

3. Snodgrass W. Tubularized, incised plate urethroplasty for distal hypospadias. J Urol 1994;151:464-5.

4. Brekalo Z, Kvesić A, Nikolić H, Tomić D, Martinović V. Snodgrass' urethroplasty in hypospadias surgery in Clinical Hospital Mostar — Preliminary report. Coll Antropol 2007;31:189-93.

5. Snodgrass W. Changing concepts in hypospadias repair. Curr Opin Urol 1999;9:513-6.

6. Samuel M, Capps S, Worthy A. Distal hypospadias: which repair? BJU Int 2002;90:88-91.

7. Al-Hunayan AA, Kehinde EO, Elsalam MA, Al-Mukhtar RS. Tubularized incised plate urethroplasty: Modification and outcome. Int Urol Nephrol 2003;35:47-52.

8. Soygur T, Arikan N, Zumrutbas AE, Gulpinar O. Snodgrass hypospadias repair with ventral based dartos flap in combination with mucosal collars. Eur Urol 2005;47:879-84.

9. Turial S, Enders J, Engel V, Schier F. Stent-free tubularized incised plate (TIP) repair of distal and mid-shaft hypospadias irrespective of age. Eur J Pediatr Surg 2011;21:168-70.

10. Sozubir S, Snodgrass W. A new algorithm for primary hypospadias repair based on tip urethroplasty. J Pediatr Surg 2003;38:1157-61.

11. Jayanthi VR. The modified Snodgrass hypospadias repair: Reducing the risk of fistula and meatal stenosis. J Urol 2003;170:1603-5. 
12. Oswald J, Körner I, Riccabona M. Comparison of the perimeatalbased flap (Mathieu) and the tubularized incised-plate urethroplasty (Snodgrass) in primary distal hypospadias. BJU Int 2000;85:725-7.

13. Roy SK, Saha K, Bhattacharjee PK, Majhi TK. Short term results of snodgrass tubularized incised plate urethroplasty in distal and mid penile hypospadias. J Indian Assoc Pediatr Surg 2003;8:226-30.

14. Shahzad Saleem M, Rasool M, Pansota MS, Tabassum SA. Comparative study between tubularized incised plate (Snodgrass) urethroplasty and reverse flap (Mathieu's) repair in distal hypospadias. Ann Pak Inst Med Sci 2012;8:96-100.

15. Guo Y, Ma G, Ge Z. Comparison of the Mathieu and the
Snodgrass urethroplasty in distal hypospadias repair. Zhonghua Nan Ke Xue 2004;10:916-8.

16. Alsharbaini R,AlmaramhyH.Snodgrassurethroplasty forhypospadias repair: A retrospective comparison of two variations of the technique. Journal of Taibah University Medical Sciences 2014;9:69-73.

How to cite this article: Mir M, Mir SA, Shahdhar M, Wani M, Moheen HA, Bhat JA. Comparative study of Mirs ' (Mushtaq and Shabir) technique of prepuce preserving minimally invasive urethroplasty with Snodgrass urethroplasty for repair of distal hypospadias without chordee...A prospective study. Indian J Plast Surg 2015;48:48-53.

Source of Support: Nil, Conflict of Interest: None declared. 